\title{
FAMÍLIAS IMIGRANTES E ESCOLAS EM BARCELONA: expectativas e realidades
}

\author{
Graça dos Santos Costa*
}

O presente artigo apresenta alguns dos resultados da pesquisa de doutorado intitulada "Diálogo família e escola em contexto de diversidade", realizada no Departamento de Didática e Organização Educativa da Universidade de Barcelona. O foco principal da pesquisa foi analisar as formas de comunicação entre famílias latinoamericanas e escolas catalanas para alcançar o apoio educativo dos menores imigrantes; descrever, compreender e interpretar as representações das famílias e de professores/a de educação primária acerca da comunicação em contexto de diversidade cultural e as implicações destas representações para o processo de construção do diálogo intercultural. O estudo de uma temática desta natureza se faz relevante dentro do âmbito das políticas global, nacional e local, através do desafio posto para a convivência e o diálogo intercultural em âmbito geral, em particular, no âmbito da educação.

Palavras chave: Escola; Família; Imigrações; Diálogo Intercultural.

\section{Introdução}

Nesse início de século, vivemos um período de muitas perplexidades, desafios e tensões. Paradoxalmente, o mundo está mais interconectado, foram quebradas barreiras alfandegárias, as tecnologias de informação e comunicação modificaram o processo de trabalho, aproximaram os mercados, as culturas e as pessoas. Nesse mesmo mundo, no entanto, consubstaciaram-se processos discriminatórios de racismo e xenofobia que atingem grupos socioculturais fragilizados economicamente e agravaram-se as dificuldades sociais, a miséria, a fome e a pobreza.

\footnotetext{
" Doutora em Pedagogia pela Universidade de Barcelona, professora da Universidade do Estado da Bahia e pesquisadora posdoutoral do Grupo de Investigação e Assessoramento Didático (GIAD) da Universidade de Barcelona. E-mail: gracacosta@gmail.com. Amelia Rodrigues, Bahia/Brasil.
} 
Dentro deste novo cenário, o crescimento da imigração ${ }^{1}$ constitui um fator que demanda novos desafios à sociedade global, especificamente a escola, com implicação para as famílias que se convertem em foco principal de atenção no contexto de diversidade cultural. A relação família imigrante e escola vêm impactando a teorização educacional contemporânea através da ênfase dada aos estudos e pesquisas sobre esse tema por autores como Madruga $^{2}$, Besalú ${ }^{3}$, Garreta $^{4}$, Carrasco $^{5}$, Essomba $^{6}$, Aparicio e Veredas $^{7}$, Bueno y Belda ${ }^{8}$, dentre outros. Educadores e pesquisadores analisam a necessidade de uma educação intercultural/ multicultural ${ }^{9}$ para a construção de uma sociedade com equidade social e para o desenvolvimento de uma cidadania e diálogo entre as diferentes culturas.

Entendendo que a educação começa na família e se prolonga na escola, que a família é um fator imprescindível na educação das crianças, sendo um locus privilegiado de socialização, espaço por excelência de relações, de motivações, de transmissão de crenças, valores e hábitos, ao mesmo tempo, a escola, instituição privilegiada de transmissão, construção

${ }^{1} \mathrm{O}$ fenômeno da imigração deve ser considerado com distintos enfoques e perspectivas, atendendo a sua complexidade, entendendo as potencialidades que podem derivar do mesmo e, neste sentido, entendendo que o fator decisivo será a educação (BUENO, José Ramón; BELDA, José Francisco (dir.). Familias inmigrantes en la escuela). O crescimento do fenômeno migratório internacional está produzindo grandes mudanças nas sociedades contemporâneas: mudanças sociais, econômicas e identitárias.

${ }^{2}$ MADRUGA TORREMOCHA, Isabel. "La escolarización de los hijos de los inmigrantes en España II".

${ }^{3}$ BESALÚ, Xavier. "Éxito y fracaso escolar en los alumnos diferentes. El alumnado de origen africano en Girona"; IDEM. Diversidad cultural y educación.

${ }^{4}$ GARRETA, Jordi. "La relación familia-escuela: una cuestión pendiente"; IDEM. "Las relaciones entre las familias inmigrantes y la escuela"; IDEM. "Escuela, familia de origen inmigrante y participación".

${ }^{5}$ CARRASCO, Silvia. Inmigración, minorías y educación: ensayar algunas respuestas y mejorar algunas preguntas a partir del modelo Ogbu y su desarrollo.

${ }^{6}$ ESSOMBA, Miguel Ángel (org.). Construir la escuela intercultural: Reflexiones y propuestas para trabajar la diversidad étnica y cultural.

7 APARICIO, Rosa; VEREDAS, Sonia. El entorno familiar de los menores de origen extranjero escolarizados en Madrid.

${ }^{8}$ BUENO, BELDA, op. cit.

${ }^{9}$ Como sinaliza BESALÚ et alii ("Los procesos de escolarización de los alumnos de origen africano en Cataluña. Un estudio de casos", p. 7), ainda que o fenômeno migratório tenha proporcionado a ocasião histórico-social que gerou o interesse pela interculturalidade, a problemática intercultural não pode ser reduzida à questão da imigração e da incorporação dos filhos dos imigrantes na escola. O debate sobre a interculturalidade foi impulsionado desde a década dos anos sessenta por diversos e complexos processos socioculturais, entre outros: a reemergência, nos anos 60 e 70, das culturas minoritárias nacionais territorializadas e sua reivindicação do direito a uma expressão cultural autônoma - tendência que nos anos 70 e 80 se traduz em reivindicação do direito à diferença e nos anos 90 desenvolve um tipo de comunitarismo hostil aos "outros", aos imigrantes, aos estrangeiros... O impacto sobre as culturas nacionais e regionais da integração européia. A acelerada mobilidade das populações, a redução das distâncias físicas, o aumento do racismo, a xenofobia e os conflitos culturais. O estabelecimento definitivo dos imigrantes na Europa do norte e a passagem de "terra de emigração" a "terra de imigração" da Europa do sul. 
e reconstrução do conhecimento, locus de vivência e convivência entre as diferentes culturas demanda colaboração dos progenitores para poder realizar sua tarefa de forma satisfatória. No entanto, a colaboração entre família e escola nem sempre é fluida ou frutífera como seria conveniente que fosse. "(...) Aunque deben considerarse espacios yuxtapuestos, a menudo lo que se percibe es la separación, la distancia, cuando no el conflicto, entre ambos"10. A falta de entendimento entre famílias ${ }^{11} \mathrm{e}$ professores dificulta o trabalho comum pelo projeto educativo dos alunos imigrantes, aumenta as desvantagens educativas dos mesmos e dificulta a colaboração e a convivência entre as escolas e os progenitores.

A comunicação entre família e escola deve ser compreendida a partir da diversidade de situações, interesse e expectativas que existem entre ambos os sistemas que podem conduzir ou gerar choques entre eles: as barreiras linguísticas que tornam a comunicação limitada, separando o pessoal da escola dos familiares dos estudantes; a falta de disponibilidade de alguns pais por questões de horário de trabalho, condições de vida; nível de escolaridade insuficiente para ajudar os estudos de seus filhos; pouco interesse ou escassa motivação para participar da vida na escola; pouco ou quase nulo conhecimento do sistema educativo dos países de acolhida; diferenças entres a organização hierárquica de ambos os sistemas; as diferenças entre sistema de crenças e regras que regem a instituição escola e as famílias; a diferença entre as expectativas e interesses dos progenitores e instituição escolar. Todos estes elementos podem dificultar a comunicação. ${ }^{12}$

Todos estes fatores culturais, linguísticos econômicos e institucionais somados às espirais negativas ou positivas que se podem gerar dentro da comunicação, através das representações, sentidos e interesses

${ }^{10}$ GARRETA, "La relación familia-escuela..., op. cit., p. 1. As mudanças sociais e culturais recentes favorecem a uma melhor relação entre família e escola: a melhora do nível de instrução, o incremento da ideologia de participação, a democratização da sociedade, a atitude dos cidadãos em relação aos serviços, reivindicando mais direitos e comprometendo-se com os serviços públicos, dentre muitos outros fatores favoreceram a lenta, porém ascendente presença das famílias nas escolas e a crenças de reivindicações da família como componente fundamental para ajudar e apoiar a escola e vice-versa. No entanto, nem sempre este papel está claro ou bem entendido, fato que gera território de controle, vigilância e ameaça de invasão de espaços, gerando uma paz armada (Maulin apud GARRETA, "Escuela, familia..., op. cit.).

${ }^{11}$ Não podemos ignorar o papel central da figura da mãe no acompanhamento da escolaridade dos filhos e filhas. Embora não tenhamos mencionado neste artigo, a análise realizada indica a pertinência de se considerar, a mediação da variável gênero com outros elementos implicados nas formas de mobilização familiar e êxito escolar.

${ }^{12}$ Cf. GARRETA, "La relación familia-escuela..., op. cit; IDEM. "Las relaciones entre... op. cit.; IDEM. “Escuela, familia..., op. cit.; BUENO, BELDA, op. cit. 
conjuntos, dificultam ainda mais a participação/comunicação. ${ }^{13}$ As percepções dos professores e professoras sobre a família determinam as relações comunicativas, assim como as percepções das famílias podem travar ou facilitar a comunicação. As famílias podem perceber as escolas com grandes expectativas, um locus de apoio e ajuda a melhora social, porém também com um sentimento insegurança, desconforto, e com certa desconfiança pela percepção de não ter as mesmas possibilidades dos espanhóis ou comunitários. Por outro lado, desde a instituição escolar se geram atribuições sobre as famílias nem sempre com um caráter positivo. São estas questões fundamentais para analisar como se geram estas espirais de expectativas e que consequências têm a aceitação, o desprezo da frustração.

La experiencia previa de estos progenitores, tanto en su vida laboral como en la escolar, además de las oportunidades del contexto, es importante por lo que supone de definición de las actitudes y expectativas que se forman respecto a los hijos e hijas (no siempre coincidentes) y por lo que representa de definición e implicación en este proyecto educativo/escolar. Pero, además, creemos que existen espirales positivas y negativas en la comunicación que se van construyendo y que acaban definiendo la relación que mantendrá una familia con la escuela y sus profesionales, distancias previas, errores de interpretación de mensajes en un determinado momento, etc. pueden conducir a una espiral negativa de relaciones por la mala predisposición de alguno de los interlocutores y, por tanto, seguir generando situaciones mal interpretadas que llevarán a un distanciamiento, cuando no conflicto, con algún profesor, con el director, con la escuela. Al contrario, una distancia inicial también puede ser superada por una espiral de experiencias positivas. ${ }^{14}$

Estes espirais positivos ou negativos da comunicação ${ }^{15}$ são gerados pelo fato de a resposta da família nem sempre acontecer de forma esperada, assim como a resposta da escola nem sempre agradar

\footnotetext{
${ }^{13}$ Cf. GARRETA, “La relación familia-escuela..., op. cit; IDEM. “Las relaciones entre... op. cit.; IDEM. "Escuela, familia..., op. cit.; IDEM, "Diversidad como problema".

${ }^{14}$ GARRETA, “La relación familia-escuela..., op. cit., p. 4.

${ }^{15} \mathrm{Na}$ Espanha a comunicação família e escola se apresenta de diferentes maneiras: através de reuniões no inicio do curso escolar que funciona como locus para apresentar os professores e expor as estratégias, regulamentos, explicar os objetivos, etc. Existe também um outro tipo de reunião individualizada que se chama tutoria na qual pode ser solicitada pelo professor ou pela família para falar os êxitos e as dificuldades das crianças. Além destes espaços legais, existem espaços não formais que funcionam como contato rápido e direto na hora da entrada e/ou saída das escolas, as celebrações escolares, etc.
} 
à família. ${ }^{16}$ Assim se faz necessário melhorar os canais de comunicação entre ambos para se conseguir melhor êxito de aprendizagem dos alunos e alunas, sobretudo, em um contexto de diversidade cultural. Neste sentido, necessita-se entender as expectativas dos progenitores sobre a escola, assim como dos professores sobre as famílias de minorias étnicas, cujo conhecimento facilitará o desenho e implementação de estratégias didáticas e curriculares para ajudar e apoiar as ações pedagógicas dos profissionais da educação, bem como a criar pontes de comunicação entre ambos os sistemas, fato que é de suma importância para melhorar o desempenho dos alunos.

\section{Expectativas das famílias imigrantes sobre a escola}

Existem vários fatores fundamentais que favorecem a integração do alunado imigrante na escola. Segundo Montón ${ }^{17}$ existem quatros âmbitos fundamentais que devem ser trabalhados para alcançar esse objetivo: a aquisição da competência linguística, o currículo, a família e o entorno. Destes âmbitos, que são de suma importância para integração dos menores imigrantes, nos interessa pesquisar a relação entre família imigrante e escola.

(...) debemos empezar por ser conscientes de que el contexto resulta esencial en el entendimiento del fenómeno y de ello deberían dar cuenta algunos discursos más pedagógicos que siguen empeñados en querer entender la escuela tan sólo con miradas desde dentro. No se trata de abandonar la escuela, sino de situarla en su contexto para entenderla. ${ }^{18}$

Situar a escola dentro do contexto significa entender o entorno, sobretudo em uma sociedade marcada por diferenças culturais. Assim uma visão focalizada no contexto, no entendimento das expectativas das famílias, na compreensão das suas crenças, dos seus valores, na análise dos seus projetos migratórios, no entendimento de suas representações sobre a escola, torna-se uma tarefa urgente para o sucesso da concretização de uma proposta intercultural no âmbito da escola.

\footnotetext{
${ }^{16}$ Os estudos apontam que as famílias não sabem até que ponto podem implicar-se na educação de seus filhos e filhas. Existe medo de invadir o terreno profissional dos professores. Existem muitos medos, desconfiança, incertezas e ameaça de invasão do território alheio.

17 MONTÓN SALES, María José. La integración del alumnado inmigrante en el centro escolar: orientaciones, propuestas y experiencias.

${ }^{18}$ GARCÍA CASTAÑO, Javier; RUBIO GÓMEZ, María; BOUACHRA, Ouafa. "Población inmigrante y escuela en España: un balance de investigación", p. 46.
} 
Entendendo que a influência do entorno é uma das condições de integração dos alunos de origem imigrante, a acolhida dos alunos imigrantes não se deve realizar em função deles mesmos como sujeitos pertencentes ao centro escolar, senão considerando também o conjunto de contexto e sistemas nos quais estes alunos se desenvolvem. Isto significa levar em consideração a família, as entidades sociais do território. ${ }^{19}$

Compartilhando a idéia de que a família ocupa um grande espaço no contexto de diversidade cultural, há uma grande quantidade de estudos que colocam a família como protagonista na vida escolar das famílias recém-chegadas. Aparício y Vereda ${ }^{20}$ apontam a influência do entorno familiar nas condições de integração das crianças imigrantes. Na mesma linha, Madruga Torremocha ${ }^{21}$ aponta que entre os fatores que mais incidem na integração das crianças imigrantes no sistema educativo espanhol estão: o idioma, a nacionalidade de origem, os hábitos do país de origem, a família, a forma e a relação que as crianças mantém com as alunos espanhóis e com os professores.

Ao analisar a expectativa das famílias de origem imigrante em relação à educação dos seus filhos e filhas, as pesquisas apontam como resultado que elas estão muito satisfeitas com o sistema educativo espanhol, valorizando positivamente o funcionamento, o modo como se desenvolvem as atividades. ${ }^{22}$ Essa valorização da escola decorre da função outorgada à educação como meio de estabilidade e integração e como via para o progresso social das famílias imigrantes. Como aponta Rego et alii,

(...) cuando los padres escolarizan a sus hijos se crean una serie de aspiraciones vinculadas al deseado progreso social en el seno de la sociedad de acogida. No cabe duda que estas expectativas condicionan las relaciones que los hijos mantienes con los docentes y con sus compañeros, y determina en alto grado sus éxitos académicos. Al mismo tiempo, no podemos pasar por alto que el gradiente de expectativas de los progenitores se encuentran estrechamente vinculados al nivel de integración de las familias en la sociedad de acogida. ${ }^{23}$

\footnotetext{
${ }^{19}$ ESSOMBA, op. cit.

${ }^{20}$ APARICIO, VEREDAS, op. cit.

${ }^{21}$ MADRUGA TORREMOCHA, op. cit.

${ }^{22}$ DEFENSOR DEL PUEBLO ESPAÑOL. Escolarización del alumnado de origen inmigrante en España: análisis descriptivo y estudio empírico; BUENO, BELDA, op. cit., dentre outros.

${ }^{23}$ REGO, Miguel A. Santos et alii. "Escuela intercultural y familias inmigrantes. Expectativas acerca de la educación", p. 7.
} 
Nessa mesma direção, outro estudo realizado por Garreta ${ }^{24}$ analisava as atitudes, as expectativas das famílias de origem africana residentes em Lérida (Espanha), relacionando-as com a origem social, o nível de estudo, o projeto familiar e a situação socioeconômica que viviam naquele momento. O estudo diferenciou três grupos: famílias sonhadoras com o projeto escolar dos seus filhos e, por consequência, com uma atitude participativa e estimulante, vendo a escola como possibilidade de melhoria social; um segundo grupo desiludidos pela situação econômica instável em que se encontravam, por isso o pensamento de regressar a seus países era muito presente, estando pouco motivados e participativos; um terceiro grupo em transição, que devido à situação que estavam vivendo, a escola não era vista como prioridade.

La actitud -definida como expectativa, nivel de aspiración, interés por los estudios de los hijos, etc. - de los padres hacia la educación, es uno de los puntos donde se concentra la influencia familiares el rendimiento escolar...el proyecto familiar, producto de la trayectoria inmigrante condiciona esa actitud y, en consecuencia, las expectativas y la función otorgada a la escuela. ${ }^{25}$

Assim, como sinaliza Garreta, a atitude da família depende do projeto migratório. ${ }^{26}$ Este condiciona e motiva o interesse das crianças, ajudando-as a abrir-se para as aprendizagens necessárias. A atitude positiva e a vontade de se adaptar facilitam o processo de adaptação escolar. Por outro lado, o refúgio, a saudade dos familiares e amigos que deixaram ou perderam, somados ao fantasma de retornar, convertem a situação atual em provisória, aumentando a dor das crianças e, por conseguinte, dificultando a aprendizagem.

Outros estudos estabelecem o grau de participação e expectativa para relacioná-las com o fator nacionalidade. De acordo com uma investigação realizada por Santos et aliii ${ }^{27}$ que tinha por objetivo saber qual era a função que as famílias imigrantes outorgavam às escolas, para os pais de origem árabe, as principais funções da escola na educação de seus filhos homens seriam a preparação para o trabalho $(44,3 \%)$ e a aquisição da cultura geral (36,4\%). Já na educação de suas filhas, as

\footnotetext{
${ }^{24}$ GARRETA, Jordi. "Expectativas educativas y sociales de las familias inmigrantes".

${ }^{25}$ Ibidem, p. 121.

${ }^{26}$ La influencia de actitudes positivas y negativas no prescinde de la influencia de la variable origen social, éste es el principal de los obstáculos que deben superar, pero es necesario constatar que hay otros factores que determinarán el éxito o fracaso escolar de los hijos de inmigrantes (Ibidem).

${ }^{27}$ Apud REGO, op. cit., p. 4.
} 
principais funções seriam fornecer uma educação que as ajude a aprender e a cumprir suas obrigações (35\%) e que lhes proporcione uma formação cultural geral (35\%). No entanto, para os pais sul-americanos, todos os seus descendentes, seja qual for o sexo, devem adquirir, por intermédio da escola, uma formação cultural básica e, além disso, aprender a cumprir todas as suas obrigações.

A falta de participação e implicação, segundo Madruga ${ }^{28}$, das famílias imigrantes não devem estar relacionadas à sua origem, mas sobretudo, com a situação de marginalização em que vivem estas famílias. Não se deve equiparar a atitude com a cultura mulçumana, pois a maioria das famílias são de baixa condição socioeconômica e educativa, sendo suas atitudes em relação à educação dos seus filhos limitadas, como habitualmente pode ocorrer em famílias nesta situação, independentemente da cultura de origem.

Outros estudos que apontam que é comum a escola culpar a falta de participação e integração das famílias imigrantes; ${ }^{29}$ que professores consideram os encontros com as famílias imigrantes pouco frutíferos em comparação com as famílias espanholas; ${ }^{30}$ e que a imagem das famílias é construída na escola como de desinteresse pela escolarização dos seus filhos e filhas. ${ }^{31}$

A partir das reflexões e destes estudos fica evidenciada a complexidade $^{32}$ em analisar a comunicação em contexto de diversidade cultural. Ficam as perguntas: As escolas estão preparadas para a participação das famílias imigrantes? As famílias imigrantes sabem como participar da escola? Existe espaço na escola para acolher as famílias imigrantes?

\subsection{Medidas socioeducativas para acolher diversidade em um entorno de imigração}

A lei Orgânica de Educação da Espanha 2/2006, de 3 de maio de 2006, estabelece a atenção à diversidade como princípio básico do

\footnotetext{
${ }^{28}$ MADRUGA, op. cit.

${ }^{29}$ CARRASCO, op. cit.

${ }^{30}$ GARCÍA ORTIZ, Puerto. "Familiarizando al profesorado con el árabe marroquí".

${ }^{31}$ PÀMIES ROVIRA, Jordi. Dinámicas escolares y comunitarias de los hijos e hijas de familias inmigradas marroquíes de la Yebala en la periferia de Barcelona.

32 Resulta importante destacar a complexidade que vive a estrutura família. Hoje em dia quase não podemos mais falar de família, mas de contexto familiares.
} 
sistema educativo para atender a uma necessidade que abarca todas as etapas educativas e todos os alunos/as. São muitos os enfoques que vêm sendo dados na Espanha - comunidades autônomas - para acolher a população imigrante. São medidas que vão desde a escolarização nas aulas de plena integração dos alunos recém chegados ao tratamento isolado destes alunos, como, por exemplo:

- Informação sobre o funcionamento da escola traduzida na língua dos imigrantes;

- Acolhimento inicial através de entrevistas com as famílias recém chegadas;

- Programas de ensino da língua e cultura de origem;

- Programa de educação compensatório orientado para o desenvolvimento de habilidades linguísticas e comunicativas;

- Garantias sociais: bolsas de ajuda a restaurantes extra-escolares;

- Medidas redistribuitivas de matricula dos alunos recém chegados em diferentes escolas (com o intuito de não formar guetos culturais);

- Tratamento das questões religiosas;

- Documentos traduzidos para todas as línguas das minorias étnicas;

- Planos de aula de acolhida traçados para ajudar a integração das famílias e os alunos recém chegados;

- Professores vêm passando por um processo de formação e assessoramento constante sobre o tema da diversidade;

- Especificamente na região que estamos estudando, Catalunha, a título local foram criados pelas prefeituras: Proyecto Joves Guia, (Mataró), del ocio infantil y juvenil (Terrassa), de la mediación intercultural, o de la atención a los menores no acompañados (Barcelona);

- Mediação intercultural; Mediadores culturais foram contratados para auxiliar a comunicação; ${ }^{33}$

- Plano de Entorno: Foi criado um programa que tem como objetivo conseguir, por meio do trabalho conjunto entre escola, família e comunidade, o êxito educativo do aluno imigrante, em todas as suas dimensões: pessoal, social, acadêmica e laboral. Neste, as famílias das minorias étnicas ocupam um papel importante, sendo criados espaços específicos para informar, acolher e integrar o ambiente escolar.

\footnotetext{
${ }^{33}$ A mediação intercultural é um recurso profissionalizado que pretende melhorar a comunicação, relação e integração entre as pessoas em um contexto de diversidade. Seu objetivo é resolver os conflitos e melhorar as relações humanas entre os grupos culturalmente distintos. No âmbito escolar, o mediador é o profissional que resolve problemas de entendimento entre professores e alunos, problemas de convivência entre alunos e problemas de dialogo e comunicação entre professores e famílias.
} 
Mesmo com todas essas proposições de integração, o diálogo intercultural ainda é visto como um grande desafio para a educação. A escola, como um espaço sociocultural, é um lócus privilegiado para aprender a conviver, um espaço por excelência no qual se deve valorizar as diferenças. No entanto, a análise da comunicação família e escola no contexto de diversidade revela que se trata de uma realidade bastante complexa, por isso qualquer que seja a tentativa de entender o diálogo intercultural entre ambos os sistemas devem primar por uma leitura plural dos referenciais que auxiliam a análise, implica, ainda, em ampliar a perspectiva, entender a comunicação escolar não unicamente através de uma análise enfocando o entorno micro social (subjetividades, identidades, representações, expectativas) ou análise centrada no contexto macro social (estrutura social, desigualdades, classes, problemas econômicos), mas compreendê-la através de uma visão sociocultural mais ampla, integradora e relacional de ambos os fatores.

\section{Um estudo de caso sobre a comunicação família e escola em contexto de diversidade}

Através da pesquisa "Diálogo família e escola em contexto de diversidade" buscamos analisar as formas de comunicação entre famílias latinoamericanas e escolas catalanas para alcançar o apoio educativo dos menores imigrantes; descrever, compreender e interpretar as representações das famílias e de professores de educação primária acerca da comunicação em contexto de diversidade cultural e as implicações destas representações para o processo de construção do diálogo intercultural.

Para realização deste propósito, abordamos este tema dentro de uma visão holística; buscamos dialogar com referenciais múltiplos na tentativa de entender os vários significados que fazem parte dessa situação, compreendendo o que está instituído (políticas e programas) para o acolhimento das famílias imigrantes no entorno educativo catalão, mas, sobretudo saber como o instituído se institui, ou seja, como estas políticas são corporificadas pelas representações dos sujeitos envolvidos, indo até o cotidiano escolar onde as políticas verdadeiramente se concretizam, onde se dão as dinâmicas das relações estudadas.

Nossa intenção em estudar a comunicação entre família escola em um entorno de diversidade cultural não é interpretar unicamente o que está instituído aqui na Espanha (políticas, programas, planos, etc.), 
especialmente em Catalunha no âmbito da educação intercultural, ou centrar em uma visão da estrutura em que se concretiza estas políticas (visão macro social), mas nosso interesse é saber como o instituído se institui e como a estrutura se estrutura, isto é, se constrói no cotidiano, dentro das dinâmicas das relações. Assim, pretendemos captar esse movimento, sem desconsiderar o contexto mais amplo ou o contexto especifico, mas ir até as práticas, aos contextos culturais, no cotidiano escolar onde as políticas verdadeiramente se concretizam, onde acontecem a dinâmica das relações e comunicações.

O método desse trabalho se funda na perspectiva qualitativa ${ }^{34}$, por considerarmos ser esta a mais adequada para compreender as representações dos professores e das famílias imigrantes acerca da comunicação na escola. Este tipo de pesquisa se fundamenta em uma perspectiva naturalística; a interpretação em contexto; maior ênfase no processo do que no produto; a valorização da apreensão dos significados atribuídos pelos pesquisados aos fenômenos estudados, à análise indutiva. ${ }^{35}$

Para compreender o processo de significação das famílias latino-americanas e dos professores de duas escolas catalanas sobre a comunicação no âmbito da escola, propomos um estudo de casos em que foram contrastadas, explicitadas e interpretadas as representações sociais de ambos os sistemas acerca da comunicação em contexto de diversidade. As técnicas utilizadas para obtenção das informações durante o processo de elaboração da presente tese foram: diário de campo, questionário, entrevista, talheres e análise de documentos. Todas estas técnicas estão interrelacionadas, sendo cada uma complementar à outra.

\subsection{Alguns resultados}

Os resultados nos revelam que se trata de uma realidade bastante complexa, por isso, buscamos analisar a diversidade de situações, interesses e expectativas que existem entre família e escola, analisando os fatores culturais, linguísticos, econômicos e institucionais na tentativa de desvelar as representações de ambos os sistemas acerca da comunicação intercultural.

\footnotetext{
${ }^{34}$ Para maior compreensão do universo estudado, método e técnicas consultar a tese doutoral: DOS SANTOS COSTA, Graça. Dialogo família escola em contexto de diversidade.

${ }^{35}$ LÜDKE, Menga; ANDRÉ, Marli. Pesquisa em educação: abordagens qualitativas.
} 
A análise dos resultados evidencia que os professores, em geral, esperam das famílias imigrantes confiança, intercâmbio de informações para esclarecer qualquer dúvida, colaboração nas atividades da escola, adaptação à língua, integração socioeducativa dos seus filhos, dedicação, interesse pelas coisas do país de acolhida e que esteja à altura das necessidades dos seus filhos e filhas. No entanto, quando perguntamos às famílias sobre o que esperavam deles (professores), as mesmas supunham acompanhamento, ajuda na integração; que orientassem os erros, que reforçassem a educação. Outros docentes ressaltavam que as expectativas familiares sobre seu papel na educação dos seus filhos e filhas dependiam do país de onde provinham, enfatizando que os comportamentos das famílias eram diferenciados conforme a nacionalidade.

Outra posição muito evidenciada por parte dos professores foi que as expectativas familiares sobre a escola estavam relacionadas com os seus projetos migratórios, sendo estes o facilitador da integração (pessoas que querem ficar, assumem uma postura mais aberta, fato que facilita a comunicação e o acompanhamento dos filhos) ou dificultador (a saudade do país de origem, a vontade de regressar, dificultam a integração socioeducativa).

É de suma importância uma revisão das crenças por parte dos professores na tentativa de desvelar os enquadramentos, as etiquetas que codificam um grupo cultural de acordo com a origem, bem como decodificar as representações das famílias sobre as identidades profissionais dos professores. Todas as representações negativas ou positivas favorecem a espirais na comunicação que podem dificultar ou ajudar no processo de apoio e ajuda família e escola.

Apesar de todas as expectativas positivas dos professores e das famílias, a comunicação ainda não é tão fluída como deveria ser. Os motivos da comunicação, partindo dos professores, giram em torno da resolução de problemas de aprendizagem e de comportamento dos alunos; ao passo que os motivos que levam a maioria das famílias a se comunicar com a escola é retroalimentar o processo de aprendizagem de seus filhos e filhas, ou seja, como um amadurecimento mútuo, como forma de acompanhar o desenvolvimento sócio-educativo dos seus filhos. Segundo grande parte das famílias, a comunicação deve ser vista 
como um espaço para compartilhar opiniões, acompanhar e resolver os problemas antes que os mesmos aflorem. ${ }^{36}$

Na tentativa de entender as dinâmicas-comunicativas entre família e escola nos deparamos com algumas barreiras que dificultam o diálogo intercultural. Apesar de todos os professores falarem a mesma língua das famílias, disponibilizando-se para fazer a comunicação em castelhano, segundo os mesmos existe in-comunicação. Para a maioria dos professores, as dificuldades comunicativas não se resumem ao idioma, mas passam por sentidos diferentes de palavras, conotações discursivas, políticas de sentidos, vontade de querer entender, vontade de escutar, as percepções das famílias sobre a escola e da escola sobre as famílias, a abertura para as informações e a vergonha de perguntar. Porém, sob o ponto de vista das famílias, a in-comunicação pode estar relacionada, também, à frieza e à burocracia e à repetição contínua das informações, ao sentimento de insegurança por parte dos professores, ao medo de serem agredidos. São estas questões fundamentais para analisar como se geram estas espirais positivas ou negativas e de que modo estas representações comunicativas facilitam o sentimento de aceitação, o desprezo da frustração no âmbito comunicativo.

Além destas barreiras idiomáticas, foram apresentadas algumas barreiras que dificultam a comunicação família e escola: barreiras culturais que dizem respeito ao desprezo e à não aceitação ao diferente, à diferença de sistemas de valores das famílias e escolas forma de educar os filhos que levam ao confronto, à formação das famílias, à bagagem cultural dos pais, dificuldades de cumprir os horários, à própria política de participação e comunicação de um país com o outro.

Uma outra barreira que aparece é a sócioeconômica. Segundo os professores entrevistados, as famílias que não resolveram seus problemas de sobrevivência não poderão desperdiçar tempo com a educação. Todos os docentes falaram que as circunstâncias econômicas são determinantes no processo de acompanhamento e comunicação família e escola; como exemplo, foram citadas as intensas jornadas de trabalho, o número de

\footnotetext{
${ }^{36}$ As tutorias (reuniões dos professores com as famílias) devem oferecer as famílias um espaço de informação, diálogo, apoio e mediação, permitindo-lhes uma maior implicação no seguimento da escolaridade de seus filhos. O espaço de tutoria não deve se resumir a explicar as notas obtidas pelos alunos ou se resumirem a explicar o mau comportamento dos mesmos, mas deve ser um lócus de ajuda e apoio e recopilação nas dificuldades de aprendizagens, apoio ao desenvolvimento à construção de saberes, mas o desenvolvimento de sua aprendizagem e a aprendizagem da vida social.
} 
pessoas que viviam em uma casa/apartamento, a atenção dedicada por parte das famílias a seus filhos. Segundo os sujeitos das pesquisas, a depender dos projetos migratórios das famílias, dos motivos que as levam a imigrar poderá facilitar/dificultar a integração socioeducativa.

Estas justificativas referentes às dissonâncias entre a socialização familiar e a escolar com base nas dificuldades econômicas das famílias que, por sua situação de pobreza, não proporcionavam motivação/ estímulo suficientes ao desempenho escolar dos filhos e filhas e/ou não dedicavam tempo ao acompanhamento educativo dos mesmos não responde ao tema complexidade da realidade estudada. Reduzir a não acompanhamento/comunicação das famílias imigrantes às escolas, a questões econômicas é focalizar o problema da in-comunicação de forma simplista, partindo de uma argumentação baseada na carência sociocultural. Estes argumentos são apoiados em um modelo idealizado de família, ou seja, ao perfil de família proveniente da classe média alta a qual era considerada adequada e favorável ao desenvolvimento integral dos alunos. Não podemos cair no erro de nos apoiar nos padrões das camadas médias para avaliar as práticas familiares de escolarização nos meios socialmente desfavorecidos.

É fundamental analisar o entorno, sem perder de vista as diferentes dimensões que este se apresenta, por isso é imprescindível a superação das análises fragmentadas fundadas unicamente na relação entre a in-comunicacao família e escola através da condição de classe e/ou diferenças culturais. É fundamental superar barreiras e romper fronteiras. Seja qual for o tipo de choque que haja na relação família e escola, deve ser algo a ser pensado e resolvido. O resultado da triangulação famíliasistema escolar-criança quem fica em menor posição é a criança.

\section{Comunicação família escola em contexto de diversidade: rompendo barreiras}

Ainda que seja prioridade legal a participação das famílias nas escolas, e que a legislação atenta a diversidade através de projetos de acolhimento... parece presentarse como una tarea difícil. La baja participación del conjunto de padres, menor entre las familias de origen inmigrante, es el escollo principal a superar, además que las distancias y resistencias son numerosas. ${ }^{37}$

${ }^{37}$ GARRETA, Jordi. “Escuela, familia de origen..., op. cit., p. 152-153. 
Para romper as barreiras é necessária uma revisão das representações que favorecem as espirais na comunicação e que podem dificultar ou ajudar no processo de apoio e ajuda à família e à escola. Superar as resistências, potencializar a participação de todas as famílias, melhorar o acesso a informação, promover novos espaços de comunicação/ aprendizagem com o objetivo de ajudar as famílias e professores na tarefa comum de educar. A construção do diálogo intercultural entre família, imigrantes e escola passa por:

- Criação de pontes de comunicação. As famílias apesar das boas intenções necessitam de tempo de adaptação à nova realidade social e escolar e necessidade de formação. Daí, qualquer projeto de acolhida a famílias imigrantes deve partir do conhecimento da realidade escolar vivida pelas famílias, do saber construído pelas suas experiências no âmbito escolar do país de acolhida e suas antigas experiências nas escolas em seus países de origem. Neste sentido, é necessária uma formação intercultural baseada na aprendizagem dialógica ${ }^{38}$ que proporcione um amplo conhecimento da estrutura participativa da escola.

- Fomento de competência intercultural. O professor/a é um dos pólos a mais na concretização do diálogo intercultural, mas é através deste pólo de mediação - entre a cultura da escola, sua própria cultura e as culturas dos alunos/as que ele exerce influência. Assim, suas atitudes e condutas, suas crenças, suas representações e suas expectativas influem de forma determinante na criação de uma proposta monocultural ou intercultural no meandro das escolas. Por isso a formação para a interculturalidade deve considerar os saberes da experiência, ultrapassando o viés unicamente acadêmico e transmissor de formação permanente, mas promover uma mudança na reflexão, na compreensão e na interpretação da própria prática, assim como na capacidade de objetivá-la a partir de lócus que promovam a autoreflexão e a reflexão compartida. ${ }^{39}$

- Revisão dos canais e motivos de comunicação. Somente medidas de acolhida de matrícula, preenchimentos de formulários, mediadores linguísticos, curso de idioma e abundante informações sobre a escola não respondem à complexidade da realidade. É necessária a criação de novas medidas de acolhida, adequando as informações aos universos

\footnotetext{
${ }^{38}$ DOS SANTOS COSTA, Graça. "Los talleres interculturales como estrategia didáctica para favorecer el diálogo entre familia y escuela en un entorno de diversidad cultural".

${ }^{39}$ TOVÍAS, Susana. Formación de los educadores interculturales. Una mirada intercultural desde el educador en formación permanente.
} 
das famílias, transformando as informações em conhecimentos/ aprendizagens. A comunicação deve ser pensada a nível curricular; os espaços de comunicação não podem ser resumir as festas e tutorias, tratando-se de um entorno novo, as famílias devem participar de outros espaços dialógicos.

Enfim, a busca do êxito educativo para todos e todas é uma tarefa urgente para todo programa que busque a igualdade de oportunidades, daí a chamada às famílias para a participação direta e constante no processo de aprendizagem social e educacional dos seus filhos. Trazer as famílias imigrantes às escolas implica em aprender a viver juntos que, por sua vez, implica viver experiência de contato com o diferente, experiência de solidariedade, de respeito, de tolerância e de diálogo. A base para o viver juntos é a comunicação, por isso a necessidade urgente de criar um clima de confiança e empatia, pautado em espirais positivas tanto por parte dos professores quanto por parte das famílias com o intuito de criar diálogo intercultural no âmbito da escola.

\section{Rompendo fronteiras: por uma epistemologia intercultural}

Como explicado anteriormente, o diálogo intercultural enfrenta numerosos barreiras, mas alguns deles dependem fundamentalmente dos relacionamentos com o outro. Como nos explica a UNESCO

El diálogo intercultural se enfrenta a numerosos obstáculos. Algunos obedecen a la dificultad de comunicarse en varias lenguas, pero otros están vinculados con el poder y la política: la discriminación, la pobreza y la explotación - que afectan en particular a las personas que pertenecen a grupos desfavorecidos y marginados - son barreras estructurales que impiden el diálogo. En muchas sociedades europeas existen asimismo organizaciones y grupos políticos que incitan al odio "al otro", "al extranjero" o a determinadas identidades religiosas. El racismo, la xenofobia, la intolerancia y todas las demás formas de discriminación rechazan la idea del diálogo y representan una afrenta permanente. ${ }^{40}$

Por isso, a construção do diálogo intercultural se configura como o processo de encontro entre pessoas de diferentes origens étnicas, culturais, religiosas e lunguísticas com a finalidade de intercambiar opiniões desde uma postura horizontal da comunicação. Esta atitude passa por mudança de mentalidade. Construir um diálogo intercultural no contexto de

${ }^{40}$ UNESCO. Libro Blanco sobre el Diálogo Intercultural "Vivir juntos con igual dignidad", p. 27. 
diversidade implica romper com uma epistemologia assimilacionista, por isso autoritária, linear, verticalizada (eu sei e tu não), fundamentalista, pautada na transmissão de informações e construir um diálogo a partir de uma mirada integradora (entre eu e tu) a partir de uma epistemologia solidária de respeito à condição humana, reconhecendo o outro enquanto produtor de conhecimento. "... conhecer é reconhecer, é progredir no sentido de elevar o outro da condição de objeto à condição de sujeito. Esse conhecimento/ reconhecimento é o que designo de solidariedade". ${ }^{41}$

Pensar a educação pautada no principio do conhecimento/ reconhecimento do outro, por isso educação intercultural, vai além de princípios e propostas, envolve uma complexidade de relações socioeducativas que acontecem no interior e fora da escola. Os espirais negativos ou positivos da comunicação entre professores, alunos e famílias potenciam ou restringem o êxito do diálogo intercultural. ${ }^{42}$ As formas de interação escola e família e a influência que tem sobre ela a própria dinâmica da instituição, seus diferentes modelos de participação e as práticas de acolhida conduzem a diferentes estruturas de espirais positivos ou negativos que parecem responsáveis pela distância entre família imigrante e escola.

(...) la colaboración entre la comunidad educativa produce sinergias favorables de la que también se ven beneficiadas estas familias (o sinergias negativas). De ahí la diversidad de formas de interactuar que creemos que existen y la importancia que otorgamos a la institución escolar y al AMPA ya que, aunque la experiencia de personas de un mismo origen sea parecida (no idéntica), el modo como son acogidos y la relación que se va construyendo no tienen por qué serlo. Mientras unos van a centros donde la participación de estas familias es valorada o cuando menos requerida, otros no son recibidos de la misma forma. ${ }^{43}$

Todo este processo conduz à construção de espirais positivos ou negativos que podem possibilitar ou impossibilitar a relação famílias imigrantes e escola. Superar as resistências, potencializar a participação de todas as famílias, promover espirais positivos, melhorar a informação, sobretudo, a comunicação é uma tarefa urgente para promover o êxito educativo do menor imigrante.

\footnotetext{
${ }^{41}$ SOUSA SANTOS, Boaventura de. Para um novo senso comum: a ciência, o direito e a política na transição paradigmática, p. 30.

${ }^{42}$ GARRETA, Jordi. "Escuela, familia de origen..., op. cit.

${ }^{43}$ Ibidem, p. 152.
} 
Entendemos que apesar de todos os passos dados, a construção do diálogo intercultural entre família e escola em contexto de diversidade passa pela escuta sensível, reconhecimento do outro e das intra-aprendizagens:

- A escuta sensível: como sabemos, a comunicação humana tem duas facetas: falar e escutar. Estas duas partes estão interrelacionadas e têm a mesma importância, mas, no entanto, muitas vezes, a escuta é vista como um ato passivo, ao passo que a fala é vista como a parte ativa da comunicação. Para construirmos uma prática dialógica, por isso horizontal da comunicação, é fundamental o entendimento de que escutar é mais que ouvir e escutar, mas envolve compromisso e aprendizagem.

Ouvir está relacionado à capacidade auditiva do ser humano, é um fenômeno biológico, está associado à capacidade de distinguir sons através das interações com o meio. Se tivermos o sistema auditivo em perfeitas condições, somos suficientemente capazes de ouvir. Escutar requer um processo mais profundo, envolvendo a interpretação das políticas de sentidos, sensibilidade ao contexto, atenção, desprendimento de verdades a priori e compreensão. Embora para escutar necessitemos ouvir, o escutar se constitui através das interações.

Escutar implica abrir-se ao outro. Sem aceitação do outro como legítimo, a escuta não poderá acontecer. Aceitação de que existem outras formas de ser e entender o mundo, outras formas de vida, significativamente diferentes das nossas formas de viver. Assim, compreendemos que para construirmos uma prática dialógica necessitamos redimensionar a escuta, construindo uma escuta sensível.

A escuta sensível se apóia na empatia, sendo fundamental saber sentir o universo afetivo, imaginário e cognitivo do outro para poder compreender de dentro suas atitudes, comportamentos e sistema de ideias, de valores, de símbolos e de mitos. A escuta sensível reconhece a aceitação incondicional de outrem... não julga, não mede, não compara. Entretanto, ela compreende sem aderir ou se identificar com as opiniões dos outros, ou ao que é dito ou feito. ${ }^{44}$

- Reconhecimento: reconhecer é mais que tolerar, mais que ouvir, reconhecer é a condição fundamental para assegurar a legitimidade do outro na convivência. A relação pautada na negação, na obediência, no preconceito, sequer pode ser considerada como relação social. Isso porque essas formas de proceder negam a condição biológica de seres

${ }^{44}$ BARBIER, René A. Escuta sensível na formação de profissionais de Saúde, p. 1. 
dependentes do amor e, assim, negam o outro como legítimo na relação social. Quando ocorre a negação do outro como legítimo na relação social, estamos diante da competição. ${ }^{45}$ Reconhecer é legitimar o outro na relação comunicativa, é ir contra qualquer tipo de fundamentalismo, significa a abertura a outras possibilidades de vida que não seja a nossa, abertura a outras formas de entender o mundo, de sentir e de ver significativamente diferentes das nossas formas de viver.

- Interaprendizagem: a interaprendizagem se constrói através da aprendizagem coletiva, em aprender com o(s) outro(s). Aprender com o(s) outro(s) implica compartir saberes em contexto de respeito. Deste modo, se torna efetivamente impossível a construção da interaprendizagem quando se começa por desqualificar e desvalorizar os saberes do outro. É impossível aprender com alguém em quem não se acredita. Por isso, para haver aprendizagem coletiva terá de existir abertura e confiança mútua. Diálogo entre duas pessoas que sabem, por isso horizontal. ${ }^{46}$ Diálogo que representa um sair-se de si, um reconstruir-se constante. "O diálogo é este encontro dos homens, mediatizados pelo mundo, para pronunciálo, não se esgotando, portanto, na relação eu-tu"47 .

Enfim, o diálogo intercultural deve ser pensado dentro do contexto macro em que está emerso, mas não poderá perder de vista os elementos condicionantes microsociais de convivência. A aprender a viver juntos passa, sobretudo, pela luta da tensão entre a indiferença/intolerância/ desrespeito pela escuta/intraprendizagem/reconhecimento das diferenças nos projetos, práticas e discursos com a diversidade. Esta aprendizagem/ convivência implica modificações organizativas e de mentalidade, através da potenciação de um currículo aberto, criação de espaços de participação e fomento de atitudes democráticas. Entendo que cada vez que nos colocamos como superiores e que impomos nossas verdades estamos construindo um ato comunicativo etnocêntrico, vertical, infeliz e desencantado. Ao passo que, cada vez que nos colocamos a escutar (não somente ouvir) e aprender estamos construindo um ato comunicativo horizontal, de respeito mútuo, por isso calcado em uma ética de reconhecimento do outro, condição sine qua non a favor da participação e convivência cidadã.

\footnotetext{
${ }^{45}$ MATURANA, Humberto. Transformación en la convivencia.

${ }^{46}$ FREIRE, Paulo. Pedagogia do oprimido.

${ }^{47}$ Ibidem, p. 178.
} 


\section{Bibliografia}

APARICIO, Rosa. Red de menores extranjeros escolarizados en Andalucía. Informe Anual realizado por el Instituto Universitario de Estudios sobre Migraciones. Madrid: Secretaria General de Asuntos Sociales, 2003.

APARICIO, Rosa; VEREDAS, Sonia. El entorno familiar de los menores de origen extranjero escolarizados en Madrid. Madrid: Universidad Pontificia de Comillas, 2003. Disponível em: www.aulaintercultural.org/IMG/pdf/comillasfeb2003.pdf. BARÁIBAR, José Manuel. Inmigración, familia y educación infantil. Madrid: Los libros de la Catarata: Madrid, 2005.

BARBIER, René A. Escuta sensível na formação de profissionais de Saúde. Conferência na Escola Superior de Ciências da Saúde - FEPECS - SES-GDF. 2002. Disponível em: www.saude.df.gov.br/FEPECS.

. "Escuta sensível na abordagem transversal", in BARBOSA, Joaquim Gonçalves (coord.). Multirreferencialidade nas ciências sociais e na educação. São Carlos: UFScar, 1998.

BESALÚ, Xavier. "Éxito y fracaso escolar en los alumnos diferentes. El alumnado de origen africano en Girona", in Cuadernos de Pedagogía, n. 315, 2002, p. 72-76. . Diversidad cultural y educación. Madrid: Síntesis, 2002.

BESALÚ, Xavier et alii. "Los procesos de escolarización de los alumnos de origen africano en Cataluña. Un estudio de casos", in GARCÍA CASTAÑO, Javier; MURIAL, Carolina (eds.). La inmigración extranjera en España. Contextos y alternativas. Granada: Universidad de Granada. 2004.

BUENO, José Ramón; BELDA, José Francisco (dir.). Familias inmigrantes en la escuela. Valencia: Universidad de Valencia, 2005.

CARBONELL, Francesc. "Desigualdad social, diversidad cultural y educación", in AJA, Eliseo et alii. La inmigración extranjera en España. Los retos educativos. Barcelona: Fundación "La Caixa", 2000, p. 99-118.

CARRASCO, Silvia. Inmigración, minorías y educación: ensayar algunas respuestas y mejorar algunas preguntas a partir del modelo Ogbu y su desarrollo. Suplementos Ofrim, Madrid, n. 11, 2004, p. 40-68.

. "La escolarización de los hijos e hijas de inmigrantes y de minorías étnicoculturales", in Revista de Educación, Madrid, n. 330, 2003, p. 99-136.

DEFENSOR DEL PUEBLO ESPAÑOL. Escolarización del alumnado de origen inmigrante en España: análisis descriptivo y estudio empírico. Madrid: Defensor del Pueblo Español, 2003.

DOS SANTOS COSTA, Graça. Diálogo entre família e escola em contexto de diversidade: uma ponte entre expectativas e realidades. Tese doutoral. Departamento de Didática e Organização Educativa. Barcelona: Universidade de Barcelona, 2009. Diponível em: http://tdx.cat/handle/10803/1374. 
DOS SANTOS COSTA, Graça.. "Los talleres interculturales como estrategia didáctica para favorecer el diálogo entre familia y escuela en un entorno de diversidad cultural", in Quaderns Digitals Revista de Nuevas Tecnologías y Sociedad, n. 71 monográfico, 2012, p. 1-14. Disponível em: www. quadernsdigitals.net.

ESSOMBA, Miguel Ángel (org.). Construir la escuela intercultural: Reflexiones y propuestas para trabajar la diversidad étnica y cultural. Barcelona: Grão, 1999. FREIRE, Paulo. Pedagogia do oprimido. Rio de Janeiro: Paz e Terra, 2005.

GARCÍA CASTAÑO, Javier; RUBIO GÓMEZ, María; BOUACHRA, Ouafa. "Población inmigrante y escuela en España: un balance de investigación", in Revista de Educación, Madrid, n. 345, 2008, p. 23-60.

GARCÍA ORTIZ, Puerto. "Familiarizando al profesorado con el árabe marroquí", in NOUAOURI, Hamdi; MOSCOSO GARCíA, Franscisco (eds.). Actas del I Congreso Árabe-Marroquí: estudio, enseñanza y aprendizaje. Cádiz: Servicio de Publicaciones de la Universidad de Cádiz, 2006.

GARRETA, Jordi. "La relació familia d'origen immigrant i escola primària de Cataluña", presentada al Simposi sobre Educació i Immigració a Catalunya 17 i 18 d'octubre de 2007, Barcelona: Fundació Jaume Bofil, 2007.

. "Las relaciones entre las familias inmigrantes y la escuela", in Ponencia del Curso: La escolarización de los inmigrantes. Cursos de Verano de la Universidad Complutense, El Escorial, 2007, p. 6 -10.

. "Diversidad como problema", in Contexto Educativo, n. 4, 2001, p. 116-175.

. "Escuela, familia de origen inmigrante y participación", in Revista de educación, n. 345, 2008, p. 133-155.

. "Expectativas educativas y sociales de las familias inmigrantes", in Papers. Revista de Sociología, n. 43, 1994, p. 115-122.

. "La relación familia-escuela: una cuestión pendiente", in IDEM. La relación familia-escuela. Lleida: Universidad de Lleida/Fund. Santa María, 2007. GARRETA, Jordi; LLEVOT, Núria. El espejismo intercultural. La escuela de Cataluña ante la diversidad cultural. Madrid: Ministerio de Educación, 2004.

LOE. Ley Orgánica 2/2006 de Educación de 3 de mayo del 2006 (BOE 4 de mayo 2006). Disponível em: http://www.mec.es. Ley Orgánica de Educación. LÜDKE, Menga; ANDRÉ, Marli. Pesquisa em educação: abordagens qualitativas. São Paulo: EPU, 1986.

MADRUGA TORREMOCHA, Isabel. "La escolarización de los hijos de los inmigrantes en España II", in Cuadernos de Información Sindical. Madrid: Confederación Sindical de Comisiones Obreras, 2002.

MATURANA, Humberto. Transformación en la convivencia. Santiago: Dolmen, 1999. 
MONTÓN SALES, María José. La integración del alumnado inmigrante en el centro escolar: Orientaciones, propuestas y experiencias. Barcelona: Graó, 2003.

PÀMIES ROVIRA, Jordi. Dinámicas escolares y comunitarias de los hijos e hijas de familias inmigradas marroquíes de la Yebala en la periferia de Barcelona. Tesis Doctoral. Barcelona: Universitat Autònoma de Barcelona, 2006.

REGO, Miguel et alii. Escuela intercultural y familia inmigrantes. Expectativas acerca de la educación. Disponível em: http://recursos.cepindalo.es/file. php/21/escuela_intercultural_y_familias_inmigrantes.pdf.

SOUSA SANTOS, Boaventura de. Para um novo senso comum: a ciência, o direito e a política na transição paradigmática. São Paulo: Cortez, 2002.

TOVÍAS, Susana. Formación de los educadores interculturales. Una mirada intercultural desde el educador en formación permanente. Disponível em: www.atriumlinguarum.org/contenido/art2_susana_tovias.pdf.

UNESCO. Libro Blanco sobre el Diálogo Intercultural "Vivir juntos con igual dignidad". Estrasburgo: UNESCO, 2008.

\section{Abstract}

\section{Immigrant families and schools in Barcelona: expectations and realities}

This article presents some of the results of the PhD thesis entitled, "Dialogue, family, and school in the context of diversity", done at the Department of Didactics and Educational Organization of the University of Barcelona. The main focus of the research was to analyze the forms of communication between Latin-American families and Catalan schools in order to gain educational support for immigrant minors; to describe, understand and interpret the representations of families and primary school teachers on communication in a context of cultural diversity and the implications of these representations for the construction process of intercultural dialogue. The study of a theme of this nature is relevant within the context of global, national and local policies, due to the challenge of coexistence and intercultural dialogue at a general level, particularly in education.

Keywords: School; Family; Immigrations; Intercultural Dialogue.

Recebido para publicação em 13/03/2012.

Aceito para publicação em 30/04/2012. Received for publication in March, 13 ${ }^{\text {th }}, 2012$. Accepted for publication in April, 30 2012. 